\title{
Vis Medicatrix naturae: does nature "minister to the mind"?
}

\author{
Alan C Logan ${ }^{*}$ and Eva M Selhub²
}

\begin{abstract}
The healing power of nature, vis medicatrix naturae, has traditionally been defined as an internal healing response designed to restore health. Almost a century ago, famed biologist Sir John Arthur Thomson provided an additional interpretation of the word nature within the context of vis medicatrix, defining it instead as the natural, non-built external environment. He maintained that the healing power of nature is also that associated with mindful contact with the animate and inanimate natural portions of the outdoor environment. A century on, excessive screenbased media consumption, so-called screen time, may be a driving force in masking awareness of the potential benefits of nature. With global environmental concerns, rapid urban expansion, and mental health disorders at crisis levels, diminished nature contact may not be without consequence to the health of the individual and the planet itself. In the context of emerging research, we will re-examine Sir J. Arthur Thomson's contention that the healing power of the nature-based environment - green space, forests and parks in particular - extends into the realm of mental health and vitality.
\end{abstract}

"What then do I mean tonight by the healing power of nature? I mean to refer to the way in which Nature ministers to our minds, all more or less diseased by the rush and racket of civilization, and helps to steady and enrich our lives. My first point is that there are deeply-rooted, old established, farreaching relations between Man and Nature which we cannot ignore without loss... there would be less "psychopathology of everyday life" if we kept up our acquaintance... we have put ourselves beyond a very potent vis medicatrix if we cease to be able to wonder at the at the grandeur of the star-strewn sky, the mystery of the mountains, the sea eternally new, the way of the eagle in the air, the meanest flower that blows, the look in a dog's eye." [1].

Professor J. Arthur Thomson - "Vis Medicatrix Nat$u_{\text {urae }}$ - Keynote Address at the Annual Meeting of the British Medical Association, 1914.

The healing power of nature - vis medicatrix naturae is an ancient medical principle that includes reference to the innate ability of the body to heal itself. While

\footnotetext{
* Correspondence: aclnd@cfs-fm.org

'Genuine Health, 775 East Blithedale Avenue, Suite 364, Mill Valley, CA 94941, USA

Full list of author information is available at the end of the article
}

acknowledging that vis medicatrix naturae can be influenced by anything from physician bedside manner to belief in placebo, medical scholars have typically defined it as an internal healing response designed to repair and rebuild [2]. Consider, for example, the healing of a fracture; "naturae" in the contemporary context is what we now recognize as the production of immune chemicals and the initiation of enzymatic reactions, a proper balance of pro- and anti-inflammatory cytokines, osteoblast and osteoclast activity etc., in the remodeling of bones. However, a century ago biologist Sir John Arthur Thomson provided an additional interpretation of the word nature within the context of vis medicatrix, defining it instead as the natural, non-built physical environment in which humans live their lives - i.e. that the healing power of nature is also that associated with mindful immersion in and contact with the animate and inanimate natural portions of our external world [1]. In our review we will re-examine the contentions of Sir J. Arthur Thomson, and in particular his suggestion that the healing power of the nature-based environment extends into the realm of mental health.

\section{Screen time and displacement of green time}

Some researchers have suggested that a significant portion of modern children and adults may be experiencing 
suboptimal levels of exposure to green space and time spent in natural settings [3]. Typically nature or natural settings are broadly defined in this context as inclusive of outdoor areas rich in vegetation and non-human animal life, including forests, urban parks, waterside areas and relatively untouched wilderness regions. Several recent studies have suggested that the expansion of screen-based entertainment (televisions, computers, video games, Smartphones) has contributed, at least in part, to the downward trend in nature-based recreation over the last two decades. While this is obviously difficult to prove, the declining visits to national and state parks, historic sites and wilderness areas - down in many locations between 25-50\% - have certainly occurred in tandem with massive increases in non-academic and non-occupational daily screen time and screen-based media consumption [4-8]. Most of the research in the area of the health-related consequences of excessive screen time has focused on implications related to obesity, cognitive performance, anxiety and depression. The results of recent prospective studies are now reporting that the accumulation of screen time is a risk factor for, and not a mere consequence of, mental health disorders [9-11]. Perceptions of cyber-based information overload are predictive of more frequent and more severe health problems [12]. Screen time, however, cannot be viewed in isolation, it can be a surrogate marker for lack of physical activity or less time spent in meaningful social interaction with a pronounced health payoff. Those experiencing high levels of cyber-based information overload are much less likely to engage in contemplative activities [12]. It remains unknown to what extent the loss of green time - time spent outdoors in nature, or at the very least, a view to nature - is itself a risk factor for mental health disorders and cognitive difficulties. Put another way, an unanswered question is whether or not the loss of contact with nature, its displacement by the screen, removes a layer of psychological resiliency.

\section{Nature, stress physiology and brain imaging}

Over 30 years have passed since scientist Roger S. Ulrich first began to examine some of the psycho-physiological changes induced by vegetation-rich scenes of nature (relative to urban scenes). His initial studies found that immediately subsequent to a required one-hour course examination, undergraduate students who viewed photographic scenes of nature (vs. urban built scenes) had a rapid improvement in positive mental outlook and a decline in reported fear and arousal [13]. These subjective reports were subsequently corroborated in separate work involving objective markers of stress physiology including electromyography (EMG), skin conductance (SC) and pulse transit time (PTT) [14]. Specifically, after viewing a stressful video on workplace accidents ("It didn't have to happen" - a video previously confirmed to elevate a stress response), participants subsequently viewed images of nature scenes or an urban built environment for 10 minutes. The physiological markers (EMG, SC, PTT) showed a consistent pattern of rapid and more complete recovery from stress/arousal upon exposure of vegetation-rich nature scenes. Ulrich was the first to use electroencephalograph (EEG) apparatus to evaluate brain wave activity while otherwise healthy adults viewed photographic scenes of nature vs. urban built scenes [15]. The results confirmed higher alpha wave activity when viewing scenes of vegetation-rich (and aesthetically unspectacular) nature, indicative of a state of relaxed wakefulness and lowered anxiety.

The original work of Ulrich has been validated to some extent by various international investigators. Nature scenes - steams, valleys, river terraces, orchids, forests, farms and bodies of water - have been shown to positively influence the same objective markers of EEG (higher alpha wave activity), EMG (decreased muscle tension) and skin conductance (decreased autonomic arousal) [16-19]. Lower levels of the stress hormone cortisol have been reported in adults subsequent to performing the same mental activities in a garden setting vs. an indoor classroom [20]. In a Japanese investigation, researchers examined physiological stress markers in 119 adults who transplanted non-flowering plants from one pot to another. Compared to adults who simply filled pots with soil, the individuals working hands-on with the plants had higher EEG alpha wave activity, decreased muscular tension as measured by EMG, as well as subjective reductions in fatigue [21].

A variety of separate Japanese studies under the umbrella terms "shinrin-yoku" (which translates as "taking in the forest air", or "forest bathing") and "forest medicine" have shown that spending time walking or contemplating in a forest setting is associated with lower cortisol, lower blood pressure, pulse rate, and increased heart rate variability. Collectively these studies have involved over 1000 subjects in studies centered in some 2 dozen different forests, and in many cases there was a control or cross-over group engaged in the same activity (physical activity and/ or contemplation) within an urban built environment $[22,23]$. Evaluation with near-infrared time-resolved spectroscopy (NITRS), a device which measures oxygen use in the brain via the reflection of near infrared light from red blood cells, reveals that 20 minutes of contemplation in a forest setting (vs. urban control) altered cerebral blood flow in a manner indicative of a state of relaxation [24]. The shift in stress physiology, lowered stress hormones in particular, has also been proposed to explain the improvement in immune functioning of subjects involved in various forest medicine studies. Compared to time spent in urban built environments, visits to forest settings have been shown to improve natural killer cell activity and the production of anti-cancer proteins [25]. 
The consistent preference for natural scenic views over urban streets is well documented, indeed the preferences for nature scenes are apparent even when they are presented for a mere $1 / 100^{\text {th }}$ of a second $[26,27]$. To add to the weight of the EEG and NITRS studies, Korean researchers recently utilized functional magnetic resonance imaging (fMRI) to investigate brain activation patterns while viewing nature [28-30]. In a series of studies, the researchers evaluated brain activity while participants viewed a set of either rural (mountains, forests) or urban built scenes for 2 minutes each, followed by a 30 second rest. To minimize the influence of intrusive thoughts and a wandering mind, every 1.5 seconds a new photo was shown. The urban scenes showed pronounced activity in the amygdala, a region that typically shows enhanced activity in response to aversive stimuli. Hyperactivity of this area has been linked to impulsivity and anxiety, while shifts from negative affect to positive mental outlook are associated with a decrease in amygdala activity. Moreover, chronic stress and the stress hormone cortisol itself may promote amygdala activity, and a consistently overactive amygdala may enhance memorization for negative vs. neutral stimuli, short-circuiting the areas that would otherwise dampen amygdala activity [31,32]. Recently it was reported that otherwise healthy urbanites (vs. rural residents) have enhanced activity in the amygdala while performing challenging cognitive tasks under conditions of perceived social stress [33].

In contrast, the Korean fMRI studies showed that nature scenes produced a pronounced activity in the anterior cingulate and the insula - increased activity in both of these areas is associated with heightened empathy and altruistic motivation [34]. This is an interesting finding when considering that the mere visualization of being in a natural setting (vs. urban center) is associated with experimental altruism in young adults [35]. Meanwhile, greater activity in the anterior cingulate is associated with emotional stability and a positive mental outlook [36], and activity in the insula is associated with love. For example, when individuals are shown photographs of loved ones while in an MRI scanner, insula activity has been shown to increase [37]. Urban scenes did not influence activity in the anterior cingulate or the insula.

\section{Nature and cognition}

In recent years there has been some scientific support to the notion that viewing scenes of nature or engaging in activities within natural settings is favorable to cognitive restoration [38-41]. Objective measurements using an Eye Position Detector System (EPDS) have shown that eye fixations, indicative of the amount of attention engaged when viewing a scene, are significantly lower while viewing highly fascinating nature scenes vs. built urban settings [42]. This suggests that natural settings are less likely to place a burden on the inhibitory pathways in the brain - i.e. in nature there is less energy expended in efforts to filter out non-pertinent stimuli. For example, after researchers induced mental fatigue in subjects via a cognitively demanding task, half of the group then viewed images that had been independently reported to be high in cognitive restoration potential (forests, water views, mountains, ocean side etc). The other half of the mentally fatigued group viewed low restoration pictures such as city streets with multiple cars, industrial zones, housing developments, factories etc. After viewing some 25 photographs of either high or low restorative potential for about 6 minutes, the subjects repeated the same cognitively demanding task for another 5 minutes. Upon repeat testing, the group who viewed the restorative nature scenes had enhanced accuracy in target detection, faster reaction time, and a higher number of correct responses to challenge vs. those viewing urban scenes [43]. The same research group has recently replicated the findings of improved reaction time (after induced mental fatigue and re-challenge with cognitive test) after viewing nature scenes rated high in fascination. They also reported overall better memory recall after viewing scenes of nature vs. built urban scenes [44]. In separate work, researchers induced mental fatigue with a series of challenging brain games designed to place demands on sustained attention. Immediately following a 35 minute period of intense cognitive effort, the subjects either took a walk (for a little less than an hour) in a vegetation-rich park or on city streets. After the walk, the cognitive tests were repeated, the results showing a significant performance difference in favor of those who had spent time in nature. An important finding of the study was that the cognitive restoration was occurring without changes in mood state per se in these otherwise healthy adults [45]. In other words, we cannot assume the cognitive gains provided by nature are simply an artifact of a more positive outlook. Recently, Korean researchers set up an experiment to evaluate the cognitive effects of a walk through a pine forest vs. downtown streets. In a cross-over design, the subjects completed cognitive and mood tests before and after a 50 minute urban or forest walk. The results showed the expected elevations in mood among the forest vs. built urban walkers; however, they also showed that only after the forest walks did participants show significant improvements in post-walk cognition [46].

Furthermore, a European study combing aerial photography and standardized cognitive assessments showed that children (aged 4-6) attending schools where play areas had more trees, shrubs and hilly terrain were least likely to present with behaviors of inattention [47]. This finding was not associated with socio-economic status of the children. In a study involving 101 public high schools 
in Michigan, classroom and primary cafeteria views were scaled for the degree and types of nature (i.e. how much green and the type of green - trees, shrubs, cut grass, athletic fields etc).. Even after controlling for socio-economic factors, class size, age of the school facilities and other factors, the results showed that classroom and cafeteria views to green vegetation were significant factors in academic performance on standardized tests. Moreover, views to trees and shrubs were associated with higher graduation rates and future plans for attendance at 4year university programs. Unlike trees and shrubs, a view to a well kept lawn was not associated with academic performance [48].

Based on the successful results using photographic images of nature, it might seem safe to presume that a virtual nature view (a wall mounted plasma TV displaying a window view to nature) might also afford cognitive benefit. Researchers examined this question in a study involving 90 young adults; subjects completed of a series of complex cognitive tasks for 30 minutes at a workstation either close to an actual window view to a nature scene, or close to a wall-mounted high-definition flat screen TV of similar size to the window with the scene depicting that of the actual nature view, or, in the third group, simply facing a blank wall. Lighting level was kept constant for each group. Each participant remained at the workstation for a 5 minute waiting period before and after the cognitive tasks, during which they could freely gaze. The actual window view held the participants attention longer than did the same view depicted on a plasma screen, and physiological markers of stress showed greatest recovery in the group who viewed the actual nature scene outside the window vs. either the plasma TV set or the blank wall. The plasma TV was better than a blank wall, but not as good as a view of nature as impeded only by a thin pane of glass [49].

Researchers from the USA first reported almost a decade ago that green outdoor activities may be associated with symptom reduction of ADHD (attention-deficit hyperactivity disorder) vs. the same activities conducted in built environments. Initial parental surveys suggested that the greenness of play areas was associated with milder symptoms of attention deficit, and that windowless indoor play areas were associated with more severe symptoms [50]. Following up with a larger study, the researchers used data from 452 parents of children formally diagnosed with ADHD and examined the setting of some 50 different activities (from reading to playing sports) to determine if there were differences in attention. Regardless of age, the presence or absence of hyperactivity in the child, economic status, geographic location with the USA, and rural or urban residence, green outdoor activities were associated with symptom reduction [51]. More recently, investigators have performed cognitive testing of attention in children with ADHD after time spent in natural vs. built environments. In a European study, researchers conducted a test of concentration after children had engaged in a period of light to moderate physical activity in a natural wooded area or a built town area. The results showed that performance on concentration tasks were higher in the wooded environment [52]. In a separate study, children with diagnosed ADD completed a series of challenging puzzles designed to tax cognitive attention, after which they walked in one of three different environments for 20 minutes. One group walked through a vegetation-rich urban park, another in a downtown built area, and the third in a residential area clustered with houses. The child was subsequently driven back to a quiet indoor setting for a series of cognitive evaluations of attention and executive functioning. The results were clearly in favor of the urban park as a means of cognitive restoration [53].

Studies have also shown that simulated drives through natural settings (forest roads) appear to be less taxing to the autonomic nervous system vs. simulated drives through urban settings [54]. In experimental research, the presence of equal levels of traffic noise was presented to adult volunteers with two different visual environments, one rich in vegetation and the other an urban built city scene. The results showed significantly less psychological distress and amplified signs of relaxation via EEG assessment when the noise was presented with views to green vegetation. In separate work involving 106 adults, researchers showed that the amount of vegetation along a highway may help mediate driver frustration. In this case the volunteers were cognitively fatigued with mental challenges, after which they proceeded on a simulated drive where the modified variable was roadside vegetation. The participants had a much higher threshold for frustration tolerance after simulated driving on roadways with more vegetation in sight. Furthermore, the researchers had the drivers work at a complex cognitive task after the differing simulated drives. Participants who drove on the high vegetation parkways were less likely to give up on the postdrive mental challenge, working at it for a significantly longer period than those who had driven in the built areas [55].

A variety of studies have also shown that indoor vegetation can also make a difference in cognitive performance. For example, researchers compared a no vegetation room to one manipulated by the addition of four plants (two small flowering plants on a window ledge, a 1-foot tall green plant on the desk and a 4-foot tall floor plant). The participants were asked to perform memory recall and complex proof-reading exercises, and those operating in the room with potted plants showed improved performance between baseline and an evaluation 10 minutes later [56]. Furthermore, Japanese researchers manipulated a small office room and reported that the presence of a 
4-foot tall corn plant improved mood and performance scores among women on a task designed to evaluate creativity [57]. Recently, researchers from Australia have reported that indoor plants placed in a classroom may influence academic scores among younger students [58]. Specifically, the researchers placed just 3 plants in half of classrooms belonging to middle-school students of 3 different Brisbane, Australia school districts. There were over 350 students involved, all of whom completed standardized academic tests prior to plant installation and again six weeks following the placement of plants in select rooms. Researchers reported significant improvements in mathematics, spelling and science among students drawn from classrooms where the plants had been placed. The results await scientific peer-review and formal publication.

\section{In vivo psychotherapy}

It has been postulated that in vivo (Latin for "within the living") counseling may, in select cases, offer some advantages over traditional office-based therapy. In the past, wilderness and other natural settings have been described as helpful for group psychotherapy, particularly when incorporated into so-called camp or wilderness therapy $[59,60]$. While there has been little in the way of proper scientific evaluation of these broad claims of success, a recent study does suggest merit to nature-based psychotherapy. In a study involving 63 patients with moderate to severe depression, participants were assigned to once-weekly cognitive-behavioral therapy in either a hospital setting or a forest setting (arboretum), while a third group acted as a control and were treated using standard outpatient care in the community. The overall depressive symptoms were reduced most significantly in the forest group, and the odds of complete remission were relatively high - 20-30\% higher than that typically observed from medication alone. Moreover, the forest therapy group had more pronounced reductions in physiological markers of stress, including lower levels of the stress hormone cortisol and improvements in heart rate variability, a marker of adequate circulatory system response to stress. The researchers conclude that the settings wherein psychotherapy is conducted are not merely 'places', rather they can become part of the therapy itself [61]. Although much more research is required, the results certainly lend credence to vis medicatrix naturae as interpreted by Sir J. Arthur Thomson, and they support the claims of ecopsychologists currently conducting psychotherapy in natural settings [62].

\section{Nature, mood and mortality}

Epidemiological investigations provide further support to the subjective and objective findings indicating that nature is a stress buffer of sorts $[63,64]$. Neighborhood greenness within urban geography is associated with individual life satisfaction and perceived satisfaction with the neighborhood itself [65]. Among over 4,500 adults, those living within a $3 \mathrm{~km}$ radius containing a high amount of green space (as measured by National Land Cover Classification Database) were less likely to experience negative health impacts of stress. Among those who had experienced recent life stressors (major losses, financial problems, relationship problems, legal issues etc), having a more dense green space within $3 \mathrm{~km}$ radius was associated with fewer health complaints vs. those with a low amount of green space [66]. A separate study involving over 11,000 adults from Denmark showed that living more than $1 \mathrm{~km}$ away from green space (forests, parks, beaches, lakes) were 42 percent more likely to report high stress and had the worst scores on evaluations of general health, vitality, mental health and bodily pain [67]. In addition, after examining the medical records of 195 family physicians, Dutch researchers reported that the annual prevalence rate of 15 of the top 24 disease states were lowest among those with the highest green space within a $1 \mathrm{~km}$ radius from home. A mere 10\% increase in green space vs. group average was associated with resiliency against chronic disease. Those with only $10 \%$ green space within $1 \mathrm{~km}$ had a $25 \%$ greater risk of depression and a $30 \%$ greater risk of anxiety disorders vs. those with the highest area of green space near the home [68].

If neighborhood greenness can positively influence mental outlook, stress physiology, and human immune system defense, it would seem reasonable to presume that neighborhood green space might be associated with lower mortality. Japanese researchers recently compared data on the percentage of forest coverage in all Prefectures and national cancer mortality rates provided by the Ministry of Health. After controlling for smoking and socioeconomic factors, there was a significant association between higher forest coverage within Prefectures and lower rates of various cancers - lung, breast, uterine, prostate, kidney and colon cancers [69]. In a study involving the residents of Shanghai, China, researchers reported that a higher proportion of neighborhood parks, gardens and green areas were associated with a reduced risk of mortality [70]. In the USA, researchers examined 5 years worth of data on stroke mortality and found that geographic green space (as measured via satellite technology) offered significant protection, while areas low in green space were associated with a significantly higher risk of stroke mortality [71]. In a recent United Kingdom study, researchers compared a land use database for green space and compared it to national mortality records from the United Kingdom Office for National Statistics. They found the same independent association between residence in the most green areas with lower rates of dying from circulatory diseases and all cause mortality. Since greater access to green space may simply 
be a surrogate marker for the other health advantages (healthcare access, nutrition, lower cumulative stress levels, cortisol etc) in affluent 'green' neighborhoods, the researchers controlled for socio-economic status. Green space, it was reported, filled in the gap in health inequalities. Among those with low income and high levels of residential greenery, the mortality rates vs. those with higher socio-economic status were similar. However, when low income was associated with little surrounding green space, the differences in mortality rates became clearly visible. The researchers concluded that green space was an independent variable capable of saving thousands of lives per year in lower income populations [72]. There is, of course, the possibility that much of the epidemiological findings in favor of green space as a variable in health, and mental health in particular, is simply due to green space providing opportunity for physical activity. Given the sound relationship between physical activity and mental health this would be a reasonable presumption. However, there is also evidence indicating that exercise conducted in outdoor settings or green space may be of more value to mental health, physical performance, and motivation to maintain exercise adherence [73-80].

\section{Nature, urban growth and environmental implications}

Within the next several decades the human transition from rural to city residence will accelerate at an even faster rate, with some 90 percent of North Americans and 70 percent of global residents projected to call a city their home [81]. Humans are incredibly social creatures, so it is not at all un-natural that urban centers should grow and thrive. There are, however, some alarming concerns with this inevitable trend. Research shows that cities are far from a panacea for mental health disorders, indeed, rates of depression, anxiety and schizophrenia are consistently reported to be higher among urban residents [33]. Based on the research discussed above, and assuming for a moment that it grows more robust in its scientific strength, the need for access to urban green space may be a mental health necessity. Access to green space and other natural settings affords opportunity for connectivity to nature, and this connectivity, in turn, may provide a layer of insulation against the psychological downsides to urban living; among almost 550 urban men and women, higher scores on the connectivity to nature scale was associated overall psychological well-being, vitality and meaningfulness in life [82]. These strong connections between nature connectivity and personal well-being are found broadly in the population - from private sector executives, high-ranking government employees, to university students, the positive relationship is evident [83]. Urban green space also provides opportunity for contemplation and mindfulness, and a recent study involving over 450 university students shows that mindfulness appears to act as a conduit between connectivity to nature and overall psychological well-being [84].

Some intriguing research suggests that there may be a two-way interaction between the potential mental health benefits of nature and the maintenance of biodiversity. A number of studies have shown that experience in nature, higher connectedness to nature, fosters pro-environmental attitudes and behaviors [85-90]. On the other hand, preliminary investigations have shown that species biodiversity is a variable in the ability of urban green space to influence mental well-being. In a United Kingdom study it was reported that the mental health benefits of 15 different urban green space settings were positively associated with a greater richness of various plant and bird species within these local settings [91]. Australian researchers have extended these results, and even after controlling for various confounders, well-being within urban neighborhoods was associated with species variety and abundance of local birds and totality of vegetation cover [92]. These are important lines of research, particularly when recent evidence suggests that internet-based learning may dilute knowledge and protective concerns related to local biodiversity, in favor of more glamorous species residing in distant locales [93]. There may be a payoff to both personal mental well-being and environmental efforts by raising awareness of potential psychological benefits of local green space and its biodiversity. Canadian researchers have recently reported that contact with nature can foster positive mood state, which in turn facilitates a sense of nature relatedness. The researchers evaluated the psychological effects of walking different routes taken by young adult volunteers - one through buildings and tunnels and the other outdoors through mixed green space - to specific locations in and around the campus. Walking for just 15 minutes through green space, as expected, was associated with more positive post-walk mental outlook. However, the researchers also discovered that the university students were unable to forecast, prior to the walks, that taking differing indoor and outdoor routes could influence mood [94]. A lack of anticipation of benefits derived from urban nature might be cause for alarm, particularly if there is indeed a legitimate displacement of nature-based contact via the omnipresent screen. Although the erosion of our connection to nature may be obscuring its perceived benefits, and research does show that young adults in university settings continue to have minimal awareness of and concern about global climate change and other environmental issues [95], there is reason for optimism - critically, the researchers also showed that walking in nature lifted mood, and mood elevation via nature exposure appears to increase 
relatedness to nature. The researchers refer to this as a happy path to sustainability, a cycle that can be maintained by fostering awareness that nature has the potential to influence mood [94].

\section{Future directions}

Our review, since it is neither a meta-analysis or systematic review, may unwittingly give the impression that nature's influence in quality of life, stress reduction, mental health and even longevity is positive and iron-clad. However, it must be acknowledged that not all studies have found benefit. For example, a recent cross-sectional study of Japanese adults (average age 52) found no association between the frequency of forest walking and the prevalence of hypertension [96]. Moreover, an examination of 49 of the largest cities in the United States did not find that green space coverage was associated with mortality from heart disease, diabetes, or lung cancer. The US cities with higher green space coverage are more sprawling and associated with greater use of motor vehicles [97]. It is also true that natural settings, forests and wilderness areas in particular, are not without risk. These settings can be the habitat of animals that require their own space, and the risk of contact with vectors carrying infectious diseases (tick-borne diseases as one example) increases in these areas [98-101]. In addition, the Japanese experience with new-growth cedar forests and their association with increasing rates of cedar pollinosis raises questions about the types of trees and plants that are most suitable for parks and urban forests [102-104]. Interestingly, a large prospective study has recently indicated that nature-based occupation (farm work) is associated with reduced risk of developing cedar pollinosis in Japan [105].

In short, there are many questions that researchers must address in the years ahead. Are there individual and cultural differences in preference for natural settings that can influence health outcomes? What might be an appropriate "dose" (duration and frequency) of nature contact? What are the mechanisms of action and what groups of individuals (e.g. children, older adults, and individuals living in deprived communities, those with mental health disorders) might have the most to gain from nature contact [106]? Are certain types of activities (e.g. gardening, walking in forest settings, contemplating in an urban park) more effective than others? How does technology and "virtual nature" fit in? To what extent are human behaviors being dictated by lack of nature contact around the home [107]? How does all of this fit into conservation efforts and global environmental issues? Research-based answers to these and other questions should provide helpful insight to policy makers and planners as our global cities expand.

\section{Conclusion}

The available evidence suggests that nature does minister to the mind, and there are more than a few scientific hints suggesting that individuals may need to be made more aware of the potential psychological benefits of nature. A century ago Sir J. Arthur Thomson maintained that the millennia had shaped the far-reaching relations between humans and nature, and that these relations could not be ignored, could not be abandoned, without loss in the realm of positive mental health. While it is difficult to determine to what extent the potential losses might be, it seems fair to suggest that the losses may be more than currently appreciated by most physicians and mental health experts. A lack of anticipated psychological benefits of time spent in nature, as recently reported among a group of young adults on an urban campus, suggests that we have indeed, as Sir J. Arthur Thomson feared, "put ourselves beyond a very potent vis medicatrix". Given the positive relationship between nature connectedness, personal well-being, and conservation/pro-environmental attitudes, the experience of even nearby nature might also provide a more sustainable path towards sustainability. Ultimately, an awareness of vis medicatrix naturae in the framework of positive psychology can sidestep the dominant negative messaging associated with sustainability and biodiversity. This otherwise fear-based approach is one wherein well-intentioned individuals may be more likely to feel disempowered and throw in the environmental towel [108]. Hopefully, further research will continue to shed light on the ways in which excessive screen time and displacement of time spent in nature might interact to influence mood and cognition. In the meantime, there is enough evidence to suggest that screen time quotas and nature as an opportunity for physical activity, contemplation and mindfulness, are worthy talking points in clinical settings.

\section{Author details}

${ }^{1}$ Genuine Health, 775 East Blithedale Avenue, Suite 364, Mill Valley, CA 94941, USA. ${ }^{2}$ Harvard Medical School, Massachusetts General Hospital, 40 Crescent St., Suite 201, Waltham, MA 02453, USA.

\section{Authors' contributions}

$A C L$ and $E M S$ contributed equal time and effort in the investigation, research and drafting of this manuscript. All authors read and approved the final manuscript.

\section{Competing interests}

The authors declare that they have no competing interests.

Received: 11 November 2011 Accepted: 3 April 2012

Published: 3 April 2012

\footnotetext{
References

1. Thomson JA: The popular lecture: vis medicatrix naturae. BMJ 1914, 2:277-279

2. Caldwell MD: Wound surgery. Surg Clin North Am 2010, 90:1125-1132.
} 
3. Groenewegen PP, van den Berg AE, de Vries S, Verheij RA, Vitamin G: Effects of green space on health, well-being, and social safety. BMC Public Health 2006, 6:149.

4. Kareiva P: Ominous trends in nature recreation. Proc Natl Acad Sci USA 2008, 105:2757-2758.

5. Pergams O, Zaradic P: Evidence for a fundamental and pervasive shift away from nature-based recreation. Proc Natl Acad Sci USA 2008, 105(7):2295-2300.

6. Pergams $O$, Zaradic $P$ : Is love of nature in the US becoming love of electronic media? 16-year downtrend in national park visits explained by watching movies, playing video games, internet use, and oil prices. J Environ Manage 2006, 80:387-393.

7. Minnesota Department of Natural Resources. Generational shift in participation 1996-2006. [http://www.dnr.state.mn.us].

8. Siikamaki J: Contributions of the US state park system to nature recreation. Proc Natl Acad Sci USA 2011, 108:14031-14036.

9. Primack B, Swanier B, Georgiopoulos AM, Land SR, Fine MJ: Association between media use in adolescence and depression in young adulthood. Arch Gen Psychiatry 2009, 66:181-188.

10. Van den Eijnden R, Meerkerk GJ, Vermulst AA, Spijkerman R, Engels RC: Online communication, compulsive internet use, and psychological wellbeing among adolescents: a longitudinal study. Dev Psychol 2008, 44:655-665.

11. Lucas M, Mekary R, Pan A, Mirzaei F, O'Reilly EJ, Willett WC, Koenen K, Okereke Ol, Ascherio A: Relation between clinical depression risk and physical activity and time spent watching television in older women: a 10-year prospective follow-up study. Am J Epidemiol 2011, 174:1017-1027.

12. Misra S, Stokols D: Psychological and health outcomes of perceived information overload. Environ Behav 2012

13. Ulrich RS: Visual landscapes \& psychological well being. Landscape Res 1979, 4:17-19.

14. Ulrich RS, Simons RF, Losito BD, Fiorito E, Miles MA, Zelson M: Stress recovery during exposure to natural and urban environments. J Environ Psychol 1991, 11:201-230

15. Ulrich RS: Natural versus urban scenes: some psychophysiological effects. Envriron Behav 1981, 13:523-556.

16. Yang F, Bao ZY, Zhu ZJ: An assessment of psychological noise reduction by landscape plants. Int J Environ Res Public Health 2011, 8:1032-1048.

17. Chang CY, Lin YH, Chou MT: Experiences and stress reduction of viewing natural environmental settings. Acta Hortic 2008, 775:139-146.

18. Chang CY, Hammitt WE, Chen PK, Machnik L, Su WC: Psychophysiological responses and restorative values of natural environments in Taiwan. Landscape Urban Plan 2008, 85:79-84.

19. Chang CY, Perng $\mathrm{J}$ : Effect of landscape on psychological and physical responses: a case study. J Ther Hortic 2000, 46:93-102.

20. Rodiek S: Influence of an outdoor garden on mood and stress in older adults. J Ther Hortic 2002, 13:13-21.

21. Yamane K, Kawashima M, Fujishige N, Yoshida M: Effects of interior horticultural activities with potted plants on human physiological and emotional status. Acta Hortic 2004, 639:37-43.

22. Park BJ, Tsunetsugu Y, Kasetani T, Kagawa T, Miyazaki Y: The physiological effects of shinrin-yoku (taking in the forest atmosphere or forest bathing): evidence from field experiments in 24 forests across Japan. Environ Health Prev Med 2010, 15:18-26.

23. Tsunetsugu Y, Park BJ, Miyazaki Y: Trends in research related to "Shinrinyoku" (taking in the forest atmosphere or forest bathing) in Japan. Environ Health Prev Med 2010, 15:27-37.

24. Tsunetsugu $Y$, Miyazaki $Y$ : Measurement of absolute hemoglobin concentrations of prefrontal region by near-infrared time-resolved spectroscopy: examples of experiments and prospects. J Physiol Anthropol Appl Human Sci 2005, 24:469-472.

25. Li Q: Kawada. Effect of forest environments on human natural killer (NK) activity. Int J Immunopathol Pharmacol 2011, 24(1 Suppl):39S-44S.

26. Tinio $P$, Leder $H$ : Natural scenes are indeed preferred, but image quality might have the last word. Psychol Aesthet Creat Arts 2009, 3:52-56.

27. Kaplan R: The green experience. In Humanscape: environments for the people. Edited by: Kaplan S, Kaplan R. Michigan, USA: Ulrich's Books; 1982:186-193.

28. Kim TH, et al: Human brain activation in response to visual stimulation and rural urban scenery pictures: a functional magnetic resonance imaging study. Sci Total Environ 2010, 408:2600-2607.
29. Kim GW, et al: Neuro-anatomical evaluation of human suitability for rural and urban environment by using fMRI. Korean J Med Phys 2011, 22:18-27.

30. Kim GW, Jeong GW, Kim TH, Baek HS, Oh SK, Kang HK, Lee SG, Kim YS, Song JK: Functional neuroanatomy associated with natural and urban scenic views in the human brain: $3.0 \mathrm{~T}$ functional MR imaging. Korean $J$ Radiol 2010, 11:507-513.

31. Ressler KJ: Amygdala activity, fear, and anxiety: modulation by stress. Biol Psychiatry 2010, 67:1117-1119.

32. St Jacques PL, Dolcos F, Cabeza R: Effects of aging on functional connectivity of the amygdala for subsequent memory of negative pictures: a network analysis of functional magnetic resonance imaging data. Psychol Sc 2009, 20:74-84

33. Lederbogen F, Kirsch P, Haddad L, Streit F, Tost H, Schuch P, Wüst S, Pruessner JC, Rietschel M, Deuschle M, Meyer-Lindenberg A: City living and urban upbringing affect neural social stress processing in humans. Nature 2011, 474:498-501.

34. Mathur VA, Harada T, Lipke T, Chiao JY: Neural basis of extraordinary empathy and altruistic motivation. Neuroimage 2010, 51:1468-1475.

35. Weinstein N, Przybylski AK, Ryan RM: Can nature make us more caring? Effects of immersion in nature on intrinsic aspirations and generosity. Person Soc Psychol Bull 2009, 35:1315-1329.

36. Brassen S, Gamer M, Buchel C: Anterior cingulated activation is related to positivity bias and emotional stability in successful aging. Biol Psychiatry 2011, 70:131-137

37. Stoessel C, Stiller J, Bleich S, Boensch D, Doerfler A, Garcia M, RichterSchmidinger T, Kornhuber J, Forster C: Differences and similarities on neuronal activities of people being happily and unhappily in love: a functional magnetic resonance imaging study. Neuropsychobiology 2011, 64(1):52-60.

38. Ottosson J, Grahn P: A comparison of leisure time spent in a garden with leisure time spent indoors: on measures of restoration in residents of geriatric care. Landscape Res 2005, 30:23-55.

39. Hung CC, Chang CY: A study of the restorative effects of urban and natural recreational settings. Acta Hortic 2004, 639:235-239.

40. Felsten G: Where to take a study break on the college campus: an attention restoration theory perspective. J Environ Psychol 2009, 29:160-169.

41. Tennessen C, Cimprich B: Views to nature: effects on attention. J Environ Psychol 1995, 15:77-85

42. Beto R: Do eye movements measured across high and low fascination photographs differ? Addressing Kaplan's fascination hypothesis. J Environ Psychol 2008, 28:185-191.

43. Berto R: Exposure to restorative environments helps restore attentional capacity. J Environ Psychol 2005, 25:249-259.

44. Berto R, Baroni MR, Zainaghi A, Bettella S: An exploratory study of the effect of high and low fascination environments on attention fatigue. $J$ Environ Psychol 2010, 30:494-500.

45. Berman $M G$, Jonides J, Kaplan S: The cognitive benefits of interacting with nature. Psychol Sci 2008, 19:1207-1212.

46. Shin WS, Shin CS, Yeoun PS, Kim JJ: The influence of interaction with forest on cognitive function. Scand J Forest Res 2011, 26:595-598.

47. Martensson F, Mårtensson F, Boldemann C, Söderström M, Blennow M, Englund JE, Grahn P: Outdoor environmental assessment of attention promoting settings for preschool children. Health Place 2009, 15:1149-1157.

48. Matsuoka R: Student performance and high school landscapes: examining the links. Landscape Urban Plan 2010, 97:273-282.

49. Kahn P, Friedman B, Gill B, Hagman J, Severson RL, Nathan G, Freier NG, Erika N, Feldman EN, Carrère S, Stolyar A: A plasma display window? The shifting baseline problem in a technologically mediated natural world. J Environ Psychol 2008, 28:192-199.

50. Taylor AF, Kuo FE, Sullivan WC: Coping with ADHD: The surprising connection to green play settings. Environ Behav 2001, 33:54-77.

51. Kuo FE, Taylor AF: A potential natural treatment for attention-deficit/ hyperactivity disorder: evidence from a national study. Am J Public Health 2004, 94:1580-1586.

52. van den Berg A, van den Berg C: A comparison of children with ADHD in a natural and built setting. Child Care Health Dev 2011, 37:430-439.

53. Faber-Taylor A, Kuo FE: Children with attention deficits concentrate better after walk in the park. J Atten Disord 2009, 12:402-409. 
54. Parsons $R$, et al: The view from the road: implications for stress recovery and immunization. J Environ Psychol 1998, 18:113-139.

55. Cackowski J, Nasar J: The restorative effects of roadside vegetation: implications for automobile driver anger and frustration. Environ Behav 2003, 35:736-751.

56. Raanaas R, Evensen KH, Rich D, Sjostrom G, Patil G: Benefits of indoor plants on attention capacity in an office setting. J Environ Psychol 2011, 31:99-105

57. Shibata S, Suzuki N: Effects of an indoor plant on creative task performance and mood. Scand J Psychol 2004, 45:373-381.

58. Byriel MG, Burchett M: Plants in the classroom can improve student performance. Interior Plantscape 2011, 37:5.

59. Levy MM: Outdoor group therapy with preadolescent boys. Psychiatry 1950, 13:333-347.

60. McFarland FW, Martin RC, Williams TA: Staff attitudes and patient behavior change on camping trip. Hosp Commun Psychiatry 1967, 18:296-298.

61. Kim W, Lim SK, Chung EJ, Woo JM: The effect of cognitive behavior therapy-based psychotherapy applied in a forest environment on psychological changes and remission of major depression. Psychiatry Invest 2009, 6:245-254.

62. Walsh B: Eco-therapy for environmental depression. Time 2009.

63. Wells N, Evans G: Nearby nature: a buffer of life stress among rural children. Environ Behav 2003, 35:311-330.

64. Verheij RA, Maas J, Groenewegen PP: Urban-rural health differences and the availability of green space. Eur Urban Regional Stud 2008, 15:307-316.

65. Vemuri AW, Grove MJ, Wilson MA, Burch WR: A tale of two scales: evaluating the relationship among life satisfaction, social capital, income, and the natural environment at the individual and neighborhood levels in metropolitan Baltimore. Environ Behav 2011, 43:3-25

66. Van den Berg A, Maas J, Verheij RA, Groenewegen PP: Green space as a buffer between stressful life events and health. Soc Sci Med 2010, 70:1203-1210.

67. Stigsdotter UK, Ekholm O, Schipperijn J, Toftager M, Kamper-Jørgensen F, Randrup TB: Health promoting outdoor environments - associations between green space, and health, health-related quality of life and stress based on a Danish national representative survey. Scand J Pub Health 2010, 38:411-417.

68. Maas J, Verheij RA, de Vries S, Spreeuwenberg P, Schellevis FG, Groenewegen PP: Morbidity is related to a green living environment. J Epidemiol Community Health 2009, 63:967-973.

69. Li Q, Kobayashi M, Kawada T: Relationships between percentage of forest coverage and standardized mortality ratios (SMR) of cancers in all Prefectures in Japan. Open Pub Health J 2008, 1:1-7.

70. Takano T, Fu J, Nakamura K, Uji K, Fukuda Y, Watanabe M, Nakajima H: Ageadjusted mortality and its association to variations in urban conditions in Shanghai. Health Policy 2002, 61:239-253.

71. Hu Z, Liebens J, Rao KR: Linking stroke mortality with air pollution, income, and greenness in northwest Florida: an ecological geographical study. Int J Health Geogr 2008, 7:20.

72. Mitchell R, Popham F: Effect of exposure to natural environment on health inequalities: an observational population study. Lancet 2008, 372:1655-1660.

73. Thompson Coon J, Boddy K, Stein K, Whear R, Barton J, Depledge MH: Does participating in physical activity in outdoor natural environments have a greater effect on physical and mental wellbeing than physical activity indoors? Environ Sci Technol 2011, 45:1761-1772.

74. DeWolfe J, Waliczek TM, Zajicek JM: The relationship between levels of greenery and landscaping at track and field sites, anxiety, and sports performance of collegiate and field athletes. HortTechnol 2011, 21:329-335.

75. Yamaguchi M, Deguchi M, Miyazaki Y: The effects of exercise in forest and urban environments on sympathetic nervous system activity. J Int Med Res 2006, 34:152-159.

76. Focht B: Brief walks in outdoor and laboratory environments: effects on affective responses, enjoyment, and intentions to walk for exercise. Res Q Exerc Sport 2009, 80:611-620.

77. Hug SM, Hartig T, Hansmann R, Seeland K, Hornung R: Restorative qualities of indoor and outdoor exercise settings as predictors of exercise frequency. Health Place 2009, 15:971-980.
78. Ryan R, et al: Vitalizing effects of being outdoors and in nature. J Environ Psychol 2010, 30:159-168.

79. Gathright J, Yamada Y, Morita M: Comparison of the physiological and psychological benefits of tree and tower climbing. Urban Forest Urban Green 2006, 5:141-149.

80. Hawkins JA, Thirlaway KJ, Backx K, Clayton DA: Allotment gardening and other leisure activities for stress reduction and healthy aging. HortTechnol 2011, 21:577-585.

81. Editors T: Street savvy. Sci Am 2011, 305:38-41.

82. Cervinka R, Roderer K, Hefler E: Are nature lovers happy? On various indicators of well-being and connectedness to nature. J Health Psychol 2012.

83. Nisbet EK, Zelenski JM, Murphy SA: Happiness is in our nature: exploring nature relatedness as a contributor to subjective well-being. $J$ Happiness Stud 2011, 12:303-322.

84. Howell AJ, Dopko RL, Passmore HA, Buro K: Nature connectedness: associations with well-being and mindfulness. Personality Indiv Diff 2011, 51:166-171.

85. Zaradic PA, Pergams ORW, Kareiva P: The impact of nature experience on willingness to support conservation. PLOS ONE 2009, 4:e7367.

86. Lohr Vl, Pearson-Mims CH: Children's active and passive interactions with plants influence their attitudes and actions toward trees and gardening as adults. HortTechnology 2005, 15:472-476.

87. Asah ST, Bengston DN, Westphal LM: The influence of childhood: operational pathways to adulthood participation in nature-based activities. Environ Behav 2011.

88. Thompson C, Aspinall P, Bell S, Findlay C: It gets you away from everyday life: local woodlands and community use - what makes a difference? Landscape Res 2005, 30:109-146.

89. Frantz CM, Mayer FS, Norton C, Rock M: There is no "I" in nature: the influence of self-awareness on connectedness to nature. J Environ Psychol 2005, 25:427-436.

90. Cheng J, Monroe M: Connection to nature: children's affective attitude toward nature. Environ Behav 2011.

91. Fuller RA, Irvine KN, Devine-Wright P, Warren PH, Gaston KJ: Psychological benefits of greenspace increase with biodiversity. Biol Lett 2007 3:390-394.

92. Luck GW, Davidson P, Boxall D, Smallbone L: Relations between urban bird and plant communities and human well-being and connection to nature. Conservation Biol 2011, 25:816-826.

93. Ballouard JM, Brischoux F, Bonnet X: Children prioritize virtual exotic biodiversity over local biodiversity. PLOS ONE 2011, 6:e23152.

94. Nisbet EK, Zelenski JM: Underestimating nearby nature: affective forecasting errors obscure the happy path to sustainability. Psychol Sci 2011, 22:1101-1106.

95. Schuetz S, Bhattarai J, Mealy B, Schuetz S, Swopes N, Harvey D, Berletic L, Knapp B, Ohlms K: What? The earth is sick? Undergraduate student awareness of environmental problems: a qualitative study. Ecopsychol 2011, 3:269-276

96. Morita E, Naito M, Hishida A, Wakai K, Mori A, Asai Y, Okada R, Kawai S, Hamajima N: No association between the frequency of forest walking and blood pressure levels or the prevalence of hypertension in a crosssectional study of a Japanese population. Environ Health Prev Med 2011, 16:299-306.

97. Richardson EA, Mitchell R, Hartig T, de Vries S, Astell-Burt T, Frumkin H: Green cities and health: a question of scale? J Epidemiol Community Health 2012, 66:160-165.

98. Karjalainen E, Sarjala T, Raitio H: Promoting human health through forests: overview and major challenges. Environ Health Prev Med 2010, 15:1-8.

99. Lane RS, Steinlein DB, Mun J: Human behaviors elevating exposure to Ixodes pacificus (Acari: Ixodidae) nymphs and their associated bacterial zoonotic agents in a hardwood forest. J Med Entomol 2004, 41:239-248.

100. Derlet RW, Carlson JR, Noponen MN: Coliform and pathologic bacteria in Sierra Nevada national forest wilderness area lakes and streams. Wilderness Environ Med 2004, 15:245-249.

101. Freer L: North American wild mammalian injuries. Emerg Med Clin North Am 2004, 22:445-473, ix

102. Morita E, Nagano J, Yamamoto H, Murakawa I, Aikawa M, Shirakawa T: Two thirds of forest walkers with Japanese pollinosis visit forests during the pollen season. Allerg Int 2009, 58:383-388. 
103. Nakae K, Baba K: Update on epidemiology of pollinosis in Japan: changes over the last 10 years. Clin Exp Allergy Rev 2010, 10:2-7.

104. Nishihata S, Murata T, Inoue S, Okubo K, Sahashi N, Takahashi H, Hirooka J, Hoshiyama Y, Murayama K, Mezawa A, Yokoyama T, Endo T, Saiga T, Saito Y: Prevalence of Japanese cedar pollinosis in Tokyo: a survey conducted by the Tokyo Metropolitan Government. Clin Exp Allergy Rev 2010, 10:8-11.

105. Nakamura K, Nagata C, Wada K, Fujii K, Kawachi T, Takatsuka N, Shimizu H: Association of farming with the development of cedar pollinosis in Japanese adults. Ann Epidemiol 2010, 20:804-810.

106. Thompson CW, Roe J, Aspinall P, Mitchell R, Clow A, Miller D: More green space is linked to less stress in deprived communities: evidence from salivary cortisol patterns. Landscape Urban Plan 2012.

107. Sijtsma FJ, de Vries S, van Hinsberg A, Diederiks J: Does 'grey' living lead to more 'green' holiday nights? A Netherlands case study. Landscape Urban Plan 2012

108. Carter DM: Recognizing the role of positive emotions in fostering environmentally responsible behaviors. Ecopsychol 2011, 3:65-69.

doi:10.1186/1751-0759-6-11

Cite this article as: Logan and Selhub: Vis Medicatrix naturae: does nature "minister to the mind"? BioPsychoSocial Medicine 2012 6:11.

\section{Submit your next manuscript to BioMed Central and take full advantage of:}

- Convenient online submission

- Thorough peer review

- No space constraints or color figure charges

- Immediate publication on acceptance

- Inclusion in PubMed, CAS, Scopus and Google Scholar

- Research which is freely available for redistribution

Submit your manuscript at www.biomedcentral.com/submit 